\title{
A BAHIA E OS SEUS FLUXOS E REFLUXOS RUMO À MÍTICA MAMA ÁFRICA: um possível campo de exercício da cooperação Sul-Sul?
}

\author{
Andre Luis Nascimento dos Santos* \\ Marcos Fábio Rezende Correia** \\ Paulo Victor de Oliveira***
}

\begin{abstract}
O presente artigo almeja refletir acerca dos fluxos e refluxos entre o Brasil e a África mítica de matriz iorubana. Como aparato metodológico, utilizaremos a sociologia dos atores e leituras pós-coloniais, interpretações das relações internacionais que nos ajudam a estabelecer os liames dialéticos entre os atores, as estruturas e as instituições em jogo. Ao longo do texto, faremos uso de relatos acadêmicos e literários trazidos pelos intelectuais das humanidades, que, ao longo do século passado, estabeleceram esses trânsitos entre o Brasil e a África iorubana, dando especial destaque para a atuação de Martiniano Eliseu do Bonfim, Pierre Verger e Agostinho da Silva. À guisa de conclusões, analisaremos a conjuntura contemporânea da cooperação Sul-Sul à luz de um evento em que o Estado brasileiro foi convidado a dar apoio à preservação da cultura iorubana na África, através da salvaguarda do sítio histórico de Oyo, qual seja, o reino mítico do Rei Xangô.
\end{abstract}

PALAVRAS-CHAvE: África, povo iorubá, candomblé, política externa, cooperação Sul-Sul.

\section{INTRODUÇÃO}

Quando, na década de 1990, o cantor Chico Cezar estreava o videoclipe "Mama África", no qual figuravam todos os membros de sua família, bem como vizinhos e amigos de infância, tendo como cenário seu vilarejo de origem no interior do Nordeste brasileiro, não o fazia sem razão. Ao vociferar em alto e bom som os versos - "Mama África, a minha mãe é mãe solteira e tem que dar mamadeira todo o dia, além de trabalhar como empacotadeira nas casas Bahia" -, de modo implícito, o seu eu poético catalisava algumas mensagens inquietantes. A nossa mítica relação com a África, os processos de retroalimentação simbólica de nossas identidades e estimas e, por fim, em

\footnotetext{
* Universidade Federal de Alagoas (UFAL), Campus de Arapiraca Av. Manoel Severino Barbosa Bom Sucesso. Cep:57309005. Arapiraca - Alagoas - Brasil. andreluisnascimentosantos@gmail.com

** Universidade Federal da Bahia (UFBA). Faculdade de Administração.

Rua Fernando José, n. 15 . Avenida Jorge Amado. Pituaçu. Cep: 41.741-090. Salvador - Bahia - Brasil. marcosrezende100@gmail.com

${ }^{* * *}$ Universidade Federal de Alagoas. Conjunto José da Silva Peixoto, Rua O, Quadra 14, n 58 , Jacintinho. Maceió - Alagoas - Brasil. paulo.omilayo@gmail.com
}

última análise, as nossas relações comuns de dependência histórica ali estavam sugeridas em um jogo de palavras, gestos e associações indiretas que nos remetem à Bahia e à sua ancestralidade negra.

Pensar o legado da diáspora africana após os processos migratórios forçados, provocados pelo tráfico negreiro ao longo da segunda metade do século XX, constituiu um verdadeiro convite para se desvelar o tanto de África que há no Brasil. Esse talvez seja o exercício intelectual cujos frutos, nos dias de hoje, começamos timidamente a colher, algo que nos tem permitido, aos poucos, criar compromissos de reparos históricos outrora negligenciados, além de adentrar em um processo civilizatório capaz de dar vênia a outras contribuições que forjaram esse país, fora do componente europeu de origem portuguesa (e, prioritariamente, de matriz católica). Em última análise, esse esforço intelectual, liderado, sobretudo, pelo campo das humanidades e pelas redes de solidariedade transnacional em torno das religiões de matriz africana, tem empreendido um verdadeiro processo de releitura étnica do país, algo que se consubstancia por meio do 
retorno às nossas origens africanas, um movimento de fortalecimento identitário desse enclave cultural historicamente vulnerabilizado na construção da narrativa brasileira.

É interessante notar que esses processos de redescoberta do Brasil a partir da memória mítica africana nos convidam, também, a desvelar o tanto de Brasil que, dia após dia, passa habitar a África, em um verdadeiro movimento de refluxo. A partir do retorno de africanos libertos, ainda no século XIX, das expedições antropológicas empreendidas por Pierre Verger, da construção do CEAO (Centro de Estudos Afro-Orientais), na então recente Universidade Federal da Bahia, e das pesquisas realizadas intelectuais que surgem a partir desse núcleo, um verdadeiro movimento de reafricanização das tradições religiosas de matriz africana passam a ser alimentadas e retroalimentadas por um fluxo comercial e migratório de brasileiros e brasileiras, em busca de legitimação intelectual e religiosa através da volta às origens. No caso da tradição jeje-nagô, ${ }^{1}$ ao se estabelecer a conexão física com a mítica Mama África, cientistas das humanidades, sacerdotes e sacerdotisas de religiões de matriz africana passam a restabelecer vínculos, fluxos simbólicos, relações comerciais e afetivas com uma pequena parcela da África, qual seja, a África Ocidental, sobretudo, a Costa do Benin

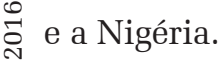

Entretanto, esses intercâmbios religiosos e intelectuais não são despidos de tensões, conflitualidades, contradições e complementações. Essa África mítica, tão almejada por religiosos brasileiros de matriz africana - preo ferencialmente o conjunto de territórios, tem$\therefore$ plos e patrimônios religiosos da dita matriz of yorubana -, sofreu, ao longo do século XX, e

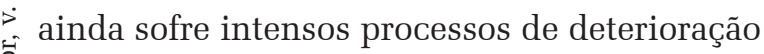

${ }^{1}$ É importante fazer essa distinção, sobretudo porque muito de outras tradições religiosas de matriz africana foram e - ainda são recorrentemente negligenciadas pela sanha his-

I toriográfica, a exemplo da herança banto e os candomblés

J de tradição angola no país. Como afirmou recentemente o

professor Julio Braga, em uma conferência magna destina-

da ao povo de Santo da Bahia, esse "nagocentrismo", que

é pujante na Bahia e no Brasil, é matriz de um verdadeiro

distanciamento de nós mesmos, de nossas origens comuns. e vulnerabilidade social, por conta de conflitos identitários decorrentes das fases coloniais e pós-coloniais, constituindo, hoje, uma minoria populacional e política se contraposta a outras religiões dominantes nos seus territórios. Nesse sentido, os grupos portadores desses legados culturais que alimentam parte do ideário mítico simbólico brasileiro, dia após dia, têm sua sobrevivência ameaçada pela expansão do islamismo, do catolicismo, das religióes neopentecostais, bem como dos tantos conflitos por territórios que ainda fazem parte do cotidiano dessa parcela de África. É diante desse cenário que a África mítica, como também real, carece da solidariedade transnacional brasileira, bem como da solidariedade de outros locais em que se deu a diáspora negra, a exemplo de Cuba, da República Dominicana, do Haiti e de algumas regiões do Caribe, como é o caso de Trinidade e Tobago e da Venezuela. Para salvaguardar esse patrimônio que se encontra em situação de risco e transmutá-lo em objeto de proteção mundial, alguns sítios históricos terão de provar a solidez desses elãs, reconstruir os fluxos e refluxos e, assim, concretizar a troca, a solidariedade ancestral.

O presente artigo - escrito a partir do diálogo de três iniciados do candomblé que, em alguma medida, exercem cargos de sacerdócio, mas também iniciados no savoir faire da academia -, almeja refletir acerca desses refluxos entre o Brasil e a África mítica, um exercício que buscará identificar as redes de solidariedade (utilitárias ou não) em que se fundam os interesses dos atores envolvidos, suas estratégias de inserção, enfim, a natureza das suas trocas reais nesse jogo, que também compõe o internacional. Como aparato metodológico, utilizaremos a sociologia dos atores e leituras pós-coloniais, duas vertentes de interpretação das relações internacionais, pois, cada uma a seu modo, nos ajuda a estabelecer os liames dialéticos entre os atores, as estruturas e as instituições em jogo. Do ponto de vista da construção histórica do fenômeno, faremos uso de relatos acadêmicos e literários trazidos 
pelos intelectuais das humanidades que, ao longo do século passado, estabeleceram esses trânsitos entre o Brasil e a África iorubana. Por fim, analisaremos a conjuntura contemporânea da cooperação Sul-Sul, à luz de um evento em que o Estado brasileiro, por meio do seu Instituto do Patrimônio Artístico e Histórico Nacional (IPHAN), foi provocado por lideranças de terreiros de candomblé, tombados na Bahia, a patrocinar a vinda do Alaafin de Oyo, liderança política e religiosa da Cidade de Oyo, na Nigéria, um encontro cujo fim principal era angariar o apoio do Estado brasileiro para a cooperação patrimonial em prol da preservação e salvaguarda do sitio histórico de Oyo, qual seja, o reino mítico do Rei Xangô.

\section{O BRASIL HABITADO NA BAHIA E SEUS ELÃS COM A MAMA ÁFRICA ANCESTRAL - os caminhos da tra- dição lorubana no Brasil}

Ao longo da história, o Ocidente foi pródigo em produzir discursos excludentes em relação ao outro, àquele que não é igual à sua imagem e semelhança, atribuindo-lhe as categorias de selvagens, exóticos e primitivos. Esse discurso de perspectiva eurocêntrica foi e ainda é utilizado como uma ferramenta de efetivação de poder, uma vez que, os textos científicos não só criam conhecimento como também a própria realidade que interessa descrever.

Ao se pensar a história do Brasil e as suas relações com o continente africano, assim como com os demais países do eixo sul, como é o caso dos próprios países latino-americanos, não é exagero considerar tais relações como historicamente construídas a partir da negação e do distanciamento. Esse aspecto de nossa formação que pode ser notado desde os tempos de nossa colonização e deixou marcas até os dias de hoje - é fruto dessa formação eurocêntrica que forjou (e ainda forja) o pensamento das elites nacionais, um movimento que mantém a mesma trajetória colonial, qual seja, o diálogo com as me- trópoles do norte e o esquecimento dos demais. A prática sistemática da arrogância, associada a pitadas de indiferença e beligerância, constitui um exercício que nos fez dar as costas para os demais países da América do Sul e esquecer as contribuições de matriz africana e indígena no nosso projeto de nação.

Entretanto, não podemos nos olvidar que, durante a sanha colonial, o Brasil foi o país que, de longe, recebeu a maior quantidade de negros na condição de escravos em todo o mundo, totalizando $38 \%$ de todos os negros arrancados do continente africano (UNESCO, 2010). É importante salientar que essa estimativa é relativa ao número dos que chegaram, sem levar em consideração a grande quantidade de mortos ao longo do percurso, ou seja, aqueles que não resistiram à longa jornada nos navios negreiros ou tumbeiros, como também eram denominados esses veículos logísticos da empresa colonial.

No que concerne aos povos vitimados pela escravidão no Brasil, sabe-se que os principais grupos que aqui chegaram foram os bantos e sudaneses. Convencionou-se denominar de bantos os indivíduos originários de diferentes etnias: os angola-congoleses e os moçambiques, localizados em Angola, no Congo, no Zaire e em Moçambique. Já os sudaneses são povos originários da Nigéria, do Daomé e da Costa do Ouro, dos quais faziam parte os iorubás (ou nagôs), os jeje, os fanti-ashanti.

Neste artigo, o objeto em evidencia nos remete aos diálogos Sul-Sul, estabelecidos nos fluxos e refluxos entre Brasil e África, sob o prisma da cultura yorubana, que, para além de pertencer a um dos principais agrupamentos que abasteceram o mercado comercial do Brasil no período da escravidão, deixou-nos um importante legado que se expressa em vários enclaves da vida comunitária, tais como a religiosidade, a convivialidade, a língua, a culinária, os gestos, os gostos, enfim, os hábitos.

Não obstante, sobre a chegada dos iorubás no Brasil, é interessante destacar que essa denominação foi uma construção da empresa 
colonial no sentido de uniformizar as distinções étnicas dos escravos negros no processo logístico de classificação e transporte marítimo. Nesse sentido, a jornada para a construção da denominada identidade iorubana foi ressignificada desde o solo africano até o território brasileiro, como fruto das necessidades, vivências e interconexões cotidianas que portugueses e escravizados estabeleceram através dos contatos iniciais. Trata-se de um processo que certamente se deu ainda nos locais de confinamento, antes mesmo da passagem pela "árvore do esquecimento", um processo de mutilação identitária que se dava nos portos mais importantes de encarceramento de negros escravizados tais como Gorée (Senegal), Cacheu (GuinéBissau), Uidá ou Ajudá (Benin), Calabar (Nigéria), Loango e Luanda (Angola). Nesse sentido, Prandi nos informa:

Formado por inúmeros grupos linguísticos e culturais que compuseram diversas etnias que abasteceram de escravos o Brasil, sobretudo os localizados na região do Golfo da Guiné e que, no Brasil, conhecemos pelos nomes genéricos de nagôs ou iorubás (mas que compreendem vários povos de língua e cultura iorubá, entre os quais os oyó, ijexá, ketu, ijebu, egbá, ifé, oxogbô, etc. (sic). Até o século XVIII, cada grupo iorubá era identificado pela sua cidade, não havendo um nome para designá-los em conjunto. Cada cidade era politicamente autônoma, cada uma governada por seu obá, ou rei, mas uma delas dominava outras, formando uma sociedade mais ampla, defendida pelo poder imperial da cidade dominante. Embora a economia fosse baseada na agricultura, caça e pesca, a população habitava as cidades, das quais Ifé, a cidade sagrada, era considerada o berço dos iorubás e da humanidade toda. Entre os iorubás o último grande império foi o da cidade de Oió, a que estavam submetidas a maioria das demais cidades. Destas cidades, duas ocupam papel especial na memória da cultura religiosa que se reproduziu no Brasil: Oió, a cidade de Xangô, e Ketu, cidade de Oxóssi, além de Abeokutá, centro de culto a Iemanjá, e Ilexá, a capital da subetnia ijexá, de onde são provenientes os cultos a Oxum e Logun -Edé. As inúmeras variantes culturais locais, tanto no caso dos bantos como dos iorubás ou nagôs, não sobreviveram como unidades autônomas e muitas foram totalmente perdidas no Brasil. Diferenças específicas foram apagadas, amalgamando-se em gru- pos genéricos conhecidos como jejes, nagôs, angola, etc. (Prandi, 2000, p. 53).

É verdade que, até chegarmos nessa nova construção identitária, a jornada de construção ideológica foi também bastante longa, e ainda hoje esse conceito se encontra em disputa. No trajeto para a construção da identidade iorubana (ou nagô), pode-se pontuar uma série de documentos e passagens da saga negra no Brasil.

Ainda no século XVII, por exemplo, o Padre jesuíta André João Antonil (1982), que viveu entre 1649 e 1716 - e foi contemporâneo do Padre Antônio Vieira, embora não tributário do seu espírito progressista -, em sua obra, observou a existência de escravos pertencentes a diferentes nações, e quis classificá-los como mais ou menos "selvagens" do que outros, algo que denota diferenciações (Antonil, 1982). Seguindo os mesmos rumos dessa construção eurocêntrica, logo após o final da escravidão, com o decreto da Lei Áurea em 1888, momentos antes do advento da República, que aconteceu no ano seguinte, a elite intelectual brasileira estabeleceu um acalorado debate sobre os componentes étnicos da nação. À época, estava em voga o debate sobre as teorias das origens e desigualdades raciais, juntamente com as ideias positivistas e evolucionistas. Verifica-se, então, um entrecruzamento de discursos, com forte influência europeia, um processo que influenciou as distintas expressões da intelectualidade nacional, tais como a literatura, a medicina, o direito e a cultura de um modo geral. Esse pautar a cultura nacional à luz da história natural e da etnologia, durante todo o século XIX, certamente forneceu o combustível necessário para o fortalecimento dos ideários racistas e conservadores que nos chegaram ao longo do século XX.

É justamente dessa tradição intelectual que descende o médico baiano Nina Rodrigues. Patologista e pioneiro nos estudos afro-brasileiros, Nina estabeleceu um novo marco de pesquisa, introduzindo o debate da supremacia racial entre os próprios negros. Amparado pelo discurso da ciência, esse autor utilizou-se 
de analises comparadas da complexidade linguística, religiosa e organizacional iorubana para defender a tese de uma pseudossuperioridade racial iorubana em relação aos bantos.

Essa talvez seja uma das primeiras matrizes "teóricas" que justificaram a construção simbólica da superioridade iorubá nas comunidades tradicionais de terreiros de candomblé localizados na Bahia. Uma construção que serviu (e ainda serve) aos interesses de pesquisadores e dos seus campos de experimentação, tradição que nasce em Nina, mas que foi também abraçada por Roger Bastide, Ruth Landes, Pierre Verger, Herskovits, dentre outros.

Essa pseudossuperioridade das matrizes iorubanas, calçada no racismo e no evolucionismo presentes nas crenças de Nina, foi capaz de criar, dentro das comunidades tradicionais de terreiros, profundos distanciamentos, disputas e negligências pela historiografia oficial. Todavia, se interpretado exclusivamente sob a ótica iorubana, o continente africano seria limitado a contornos de homogeneidade que não correspondem à sua verdadeira diversidade étnica, linguística e cultural que tanto contribuiu para a formação da identidade brasileira.

Ao se utilizar alegoricamente da manutenção da pureza linguística, como também da estrutura sociocultural e religiosa dos iorubás, Nina (2004) terminou por elegê-los como tipo ideal para a compreensão da presença negra no Brasil. Tal escolha levou mais em conta sua proximidade de pesquisador ${ }^{2}$ com a realidade iorubana que necessariamente a inexistência de elementos identitários bantos na formação do país.

Na obra Falares Africanos na Bahia, Castro (2001) nos auxilia a compreender melhor esse processo, ao demonstrar que, diferentemente das levas de negros bantos escravizados que chegaram ao Brasil para o trabalho na la-

2 Soma-se a sintonia mais fina desse pesquisador com a realidade iorubana, já que esse contingente se estabeleceu na capital baiana e tinha maior possibilidade de diálogo entre si, o que facilitava a manutenção de seus traços culturais característicos; já os bantos - que chegaram ao Brasil em processos diaspóricos anteriores aos dos iorubás - foram fixados nas lavouras do interior, com maior distanciamento entre seus grupos originários. voura a partir do século XVI, os iorubás, por sua vez, adentraram ao país em um momento mais agudizado do tráfico negreiro. Trata-se de um processo que se deu já na última fase do tráfico transatlântico, no século XVIII e XIX, no qual os iorubás foram empregados, em sua maioria, em trabalhos urbanos e domésticos na cidade de Salvador.

Ademais, afirma Castro, como, diferentemente dos bantos, os iorubanos se estabeleceram em centros urbanos, eles tiveram melhores condições para preservar seus falares e sua religião. Isso criou, no Brasil, uma falsa constatação de superioridade dos iorubás, privilegiando-se, assim, a cultura sudanesa e desqualificando os povos de cultura banto.

[...] como a cidade de Salvador também é tratada pelo seu antigo nome de Bahia, não foi difícil estender a influência yoruba a todo o Estado, da mesma maneira que o termo nagô passou a ser genericamente usado como sinônimo de africano ou de qualquer língua africana na Bahia (Castro, 2001, p. 54).

A vinda desse grande contingente iorubano para a Bahia estabeleceu uma relação de aproximação desse estado da federação brasileira com a África ancestral e consolidou um caminho de diálogos interculturais. Nesse sentido, tanto para o bem como para o mal, a tradição iorubá, sedimentada na Bahia, foi capaz de alimentar fluxos e refluxos em prol de uma ideia primária de cooperação Sul-Sul, uma construção que envolveu aspectos de mercado, mas, também, outras solidariedades de natureza afetiva e identitária.

É justamente a partir do século XIX, ainda antes do final da escravidão, que se inicia o refluxo de negros brasileiros ao continente africano, sobretudo, para a região do Golfo do Benin (Benin, Nigéria, Togo, Gana). Eram majoritariamente negros libertos, que retornaram por vontade própria, mas havia também os deportados, como foi o caso dos apenados na Revolta dos Malês, ocorrida na Bahia em 1835. Esses negros criaram, no continente africano, comunidades "brasileiras", que foram denomi- 
nadas de Agudás ${ }^{3}$ (ou Amarôs) na Nigéria, no Benim e no Togo; no caso dos que retornaram para Gana, foram e denominadas Tabons.

Em meio a esse refluxo e no esteio dos processos de afirmação da cultura iorubana é que surge a importância das contribuições do baiano Martiniano Eliseu do Bonfim. De forma concreta, esse talvez seja um dos principais atores religiosos no processo de reconstrução simbólica e ritualística dos elãs entre o Brasil e a África mítica iorubana. Ojeélàdé (nome em nagô iorubá de Martiniano Eliseu do Bonfim) não poupará esforços em prol da sua busca pela reafricanização da religião afro-brasileira, um exercício que servirá para reforçar o conceito nagô e alimentar a pureza do candomblé da nação iorubá. Filho de Eliseu do Bomfim, Àreòjè (nome em nagô-iorubá), e de Felicidade Silva Paranhos, Majèngbásá (nome em nagô-iorubá), ambos escravos libertos da cidade de Salvador da Bahia em 1859, Martiniano foi levado para Lagos por seu pai em 1875, e lá ele frequentou a Escola Presbiteriana Faji, onde aprendeu inglês e iorubá.

Não sem razão, ao analisar o contexto da época, o antropólogo Julio Braga (1995) no seu livro Gamela do Feitiço - repressão e resistência nos candomblés da Bahia, dedica parte considerável da obra para a análise da trajetória de Martiniano, um ator negro que fez as vezes de verdadeiro diplomata entre as granذ des casas e a sanha de antropólogos da época, a exemplo de Nina Rodrigues, Edson Carneiro e Ruth Landes. Entre as trocas de saberes e o ganho de legitimidade por parte das comunidades tradicionais junto a atores da academia, o Martiniano bem soube criar estratégias de in\& serção do candomblé na narrativa nacional,

$>{ }^{3}$ Cabe salientar que o termo Agudá estava associado aos ఈ̃ católicos; e como a religião católica era identificada com os brancos, por diversas vezes os negros brasileiros que retornaram à África eram vistos como "brancos" de uma స్ nova espécie, em que a cor da pele não interferia na clas- sificação. Pierre Verger (1987) ressalta o fato de que os neI gros brasileiros, ao retornarem à região da África Ociden-

ک tal, provocavam sentimentos hostis da população local, porque eles se enxergavam como diferentes e superiores aos africanos. Isso era visto pelos africanos como algo inexplicável e incompatível, uma vez que esses negros brasileiros tinham sido escravos no Brasil. um esforço sem precedentes se levarmos em conta a baixa aquiescência das contribuições negras no projeto nacional no Brasil da época.

Martiniano não foi o único ator negro da época que travou esse transito e constituiu fluxos e refluxos rumo à África iorubana. Ele é um caso exemplar das negociações constituídas nessa época, mas não podemos nos esquecer de figuras como Bamboche Obiticó, Felisberto de Souza, Mãe Aninha, Antônio das Cobras, dentre tantos outros que, figuraram como guardiões do patrimônio imaterial legado pela herança africana e que, hoje, figuram como ancestrais de um povo.

\section{PIERRE VERGER E AGOSTINHO SANTOS, DOIS ESTRANGEIROS E A SEGUNDA GERAÇÃO DE RETORNO À MÍTICA MAMA ÁFRICA: a sistema- tização dos fluxos e refluxos com a África}

Na construção do olhar brasileiro rumo à África mítica, dois atores, de inspiração de esquerda, mas de tradições intelectuais distintas, foram fundamentais na continuidade desses elãs, na metade do século XX: o francês Pierre Verger e o português Agostinho da Silva. Respondendo aos reclames de suas respectivas trajetórias e visões de mundo, eles empreenderam um verdadeiro movimento político de aprofundamento dos diálogos do Brasil com a África, um processo que gerou frutos significativos na construção dessa narrativa ainda em formação.

A descoberta de Pierre Verger da presença africana na cultura brasileira (a partir de sua estada na Bahia entre 1946 e 1948 e sua ida ao Daomé, então colônia francesa, em1948, sob os auspícios do Institut Français d'Afrique Noire, IFAN) coincidiu com um período em que a África havia sido "distanciada" do candomblé baiano. Os últimos especialistas religiosos com formação nas terras iorubanas haviam falecido - notadamente Felisberto de Souza e Martiniano do Bonfim. 
Apesar de o "estado de espírito" da cultura erudita brasileira, desde a invenção do Brasil, ter sido o desprezo pelos elementos africanos - e o passo à frente de Gilberto Freyre, em Casa Grande e Senzala (2006) ter aberto espaço para a mestiçagem, mas não para a africanidade -, as sociedades de culto a orixá e egungum mantiveram-se, no máximo possível, em contato com o continente africano. Não apenas um contato abstrato, mas real, através do trânsito de pessoas, informações e objetos.

Precisamos ter cuidado para sermos entendidos ao evocar a Mama África mítica. Compreendemos mito como uma forma poético-narrativa, que pode tudo ou nada ter a ver com mistificação. O mito age poeticamente, ao unir natural e sobrenatural (humanos e orixás) na construção da narrativa.

A ligação efetiva com a África era uma realidade enquanto a marinha mercante mantinha rotas entre as duas costas atlânticas. O comércio interatlântico enviava, do Brasil para a costa africana, carne seca, aguardente de cana, açúcar e fumo de tabaco; e de lá trazia tinturas, ráfia, cauris e outros objetos de uso ritual. À medida que essas rotas foram minguando (até desaparecerem), as ligações com a África foram se transformando de efetivas em afetivas. A respeito dessas rotas comerciais, Alberto diz que:

Essa mudança foi o resultado de transformações que começaram na África Ocidental no final do século XIX. O estabelecimento de formas mais diretas de domínio colonial endureceu as atitudes raciais e aumentou a penetração comercial de firmas europeias, o que gradualmente acabou com os negócios independentes dos comerciantes agudás. Apenas alguns conseguiram manter suas atividades durante a década de 1920 e no começo da década de 1930. No final dos anos 30, a Segunda Guerra Mundial cortou os últimos contatos que existiam entre a Bahia e a África Ocidental (Alberto, 2011, p. 64).

Essa fase coincide com a dinâmica do candomblé pós-abolição. Uma vez assegurada a liberdade religiosa pela constituição republicana, o candomblé, não considerado religião, passa a ser alvo de diversas modalidade de perseguição. Na Bahia e no Rio de Janeiro, houve o controle policial e jornalístico; em Alagoas, verifica-se a invasão sangrenta de milícias urbanas a templos de matriz africana (o chamado Quebra do Xangô em 1912); no Recife, havia a medicina e as tipologias do serviço de saúde mental. Essa foi a deixa para que os atores sociais, até então oprimidos, passassem a manter redes de diálogos junto a atores da cultura erudita, um exercício lento e ainda em curso no longo processo de reconhecimento dessa identidade de raça e religiosa.

A convivência com personalidades africanas (ou de íntimo contato com o continente), ativas até os meados dos anos 1940, passa a ser um componente crucial para a legitimação das sociedades de culto de matriz iorubana. Não sem razão, verifica-se, na memória coletiva do povo de santo, como também nos estudos antropológicos sobre o negro no Brasil, a menção frequente aos nomes desses atores sociais cuja descendência africana oportunizou a manutenção dos trânsitos. À necessidade intrínseca de os candomblés conservarem o ritual alia-se a necessidade social imposta de legitimação por via da "pureza ritual", que advinha da ascendência africana, e a manutenção desses laços.

A partir da Bahia, Verger rumou para as terras iorubanas à procura das raízes da cultura que conhecera no Brasil. Realizou estudos comparados da ritualística dos cultos de orixá nas duas costas atlânticas. Sua obra foto-etnográfica é o atestado de fidedignidade do candomblé em relação às seculares tradições iorubanas. Em relação a uma África cada vez mais distante, estavam ali impressas, em preto e branco - para utilizar a expressão de Brandão e Motta (2002) - "a lei e os profetas".

Embora não seja nosso interesse, neste momento, realizar uma digressão acerca da importância das obras etnográficas e antropológicas para o candomblé, podemos dizer que esses escritos servirão como vias de comunicação para uma África procurada e só acessível para muitos através desses documentos. Durante algumas décadas, as viagens interatlân- 
ticas eram feitas majoritariamente por pesquisadores. Os frutos dessas pesquisas servirão de fonte de tradição para uns e de confirmação dos costumes para outros. Nessa segunda acepção, em 1952, Verger seria portador da outorga - por Alafin Oyo - do título de Iyá Nassô - sacerdotisa membro do staff real e oye ${ }^{4}$ que pertencera a uma das fundadoras do candomblé ketu baiano - concedido a Mãe Senhora, sacerdotisa sênior do Axé Opô Afonjá.

Para a cultura erudita, esse movimento possibilitou outra leitura da cultura brasileira. Se, a partir da obra de Gilberto Freire, a mestiçagem havia entrado como componente matricial da cultura brasileira (o que conservava a noção de identidade cultural una, apenas a deslocando da matriz ibérica para uma matriz mestiça), a existência de uma cultura religiosa autonomeada "africana" (sendo essa autodefinição comprovada em preto e branco nas fotografias e tipos) apontava para uma cultura brasileira multi-identitária.

Outro ponto importante foi o encontro de Verger com os agudás, como eram chamados os indivíduos que, após o cativeiro no Brasil, rumaram para as terras iorubanas, mantendo a memória de sua trajetória diferenciada e uma cultura que os distinguia daqueles outros que não haviam passado pela escravidão e pelo "retorno". Essa comunidade de brasileiros fora do Brasil desponta na produção intelectual e, pelo começo dos anos 1960, torna-se um interesse de Estado.

O contexto político brasileiro de então, em parte modernizante, em parte populista, já demonstrava uma aproximação com aspectos ڤ' até então "esquecíveis" da formação identitáa ria brasileira. No quinquagésimo aniversário ờ de consagração sacerdotal da já citada Mãe Senhora (em 1958), uma delegação representou o presidente da República, Juscelino Kubitschek.

Em 1959, pela atuação política e intelectual do português Agostinho da Silva, foi

${ }^{4}$ Oye é um cargo ritualístico atribuído a um iniciado da tradição jeje nagô sob a outorga de um sacerdote devidamente autorizado para tal. fundado o Centro de Estudos Afro-Orientais (CEAO) da Universidade Federal da Bahia (UFBA), o primeiro do gênero. Agostinho da Silva se esforçou por criar o CEAO muito mais pelo desejo de objetivá-lo como instrumento político no âmbito local, nacional e internacional, no que se referia às estratégias de ampliação dos diálogos com a África do que pelo interesse acadêmico propriamente dito (Teles dos Santos, 2005). Nesse cenário construído, não demorou muito a ser elevado à condição de assessor da presidência da República para assuntos diplomáticos, no tocante aos países africanos, no governo de Jânio Quadros. Não seria exagero afirmar que foi de sua cepa a primeira geração de políticas de cooperação Sul-Sul do Brasil com a África, um movimento político que se desdobrou em acordos internacionais, a exemplo do tratado com o Senegal, bem como a disponibilização de uma série de bolsas de estudo, estabelecendo-se, assim, os intercâmbios acadêmicos entre estudantes e professores brasileiros e africanos.

Não sem razão, esse período, em que atuou como assessor do governo Quadros, coincide, exatamente, com o período em que o Brasil começou a aplicação de nova política exterior voltada, notadamente, para os países do Sul. Em outubro de 1961, o presidente Jânio Quadros publicou "Brazil's New Foreign Policy" onde define a política diplomática do Brasil em relação à África .

\begin{abstract}
Nós estamos ligados àquele continente pelas nossas raízes étnicas e culturais e compartilhamos o seu anseio de criar uma posição independente no mundo atual. [...] podemos dar às nações do continente africano um exemplo da ausência total de preconceito racial, junto com uma prova de progresso sem ferir os princípios de liberdade, nós estaremos contribuindo para a integração efetiva de todo um continente num sistema ao qual somos ligados pela nossa filosofia e tradição histórica (Quadros, 1961).
\end{abstract}

Numa época de luta por independência de nações africanas, o Brasil põe-se como mediador entre a África e o Ocidente, os "dois mundos” dos quais o Brasil oficialmente, na- 
quele momento, requer fazer parte.

O momento simbolicamente mais marcante dessa nova política externa brasileira foi a visita de Ayodele Romana da Conceição. Nascida em Pernambuco, dona Romana rumou para Lagos (Nigéria) com a família, em meados de 1899 e 1900, quando era ainda uma criança. Descoberta por Verger logo no início de suas viagens pelas terras iorubanas - e frustradas as tentativas de trazê-la ao Brasil -, ele manteria contato com o adiado cultural Antônio Olinto, à época lotado na neófita Embaixada do Brasil na Nigéria recém-independente. Entre 17 de maio e 8 de agosto de 1963, dona Romana, convidada especial do Itamaraty, visitaria o Brasil. Foi recebida no Palácio do Planalto pelo presidente João Goulart. Foi, naquele momento, junto de Mãe Senhora - até onde sabemos - a única mulher negra a receber algum tipo de deferência por parte do Estado.

Em seu tour, Dona Romana visitou Recife onde nasceu e reencontrou, mais de sessenta anos depois, suas parentes Sinhá e Iaiá, célebres tias do Pátio do Terço. Essa visita se deu alguns meses antes do golpe de Estado de 1964, quando toda a política exterior brasileira foi reformulada.

\section{A POLÍTICA EXTERNA BRASILEIRA E OS DESCONTÍNUOS DIÁLOGOS COM A MAMA ÁFRICA: por uma crítica às intermitências}

Ao longo do século XX, a política externa brasileira direcionada aos países africanos foi pautada por impulsos e descontinuidades (Hirst, 2010; Saraiva, 2012; Milhorance, 2013). Nesse sentido, a historiografia recente da diplomacia brasileira pontua três ondas de impulsos descontínuos rumo aos países da África, momentos que respondem aos contextos da inserção brasileira no sistema internacional e suas intensões de potência.

O primeiro desses momentos remonta, justamente, aos anos 1960, quando dos gover- nos de Jânio Quadros e João Goulart. Nesse período, ambos os presidentes, dentro das suas particularidades, propugnavam uma política externa de não alinhamento, pautando a questão do subdesenvolvimento como tema mais nevrálgico para os países do terceiro mundo, uma consequência histórica das relações desiguais havidas entre o Norte e o Sul. Essa era, em verdade, uma primeira vinculação do Brasil à agenda Sul-Sul, uma escolha política intimamente relacionada com as redes de articulação criadas a partir das conferências de Bandung (1955) e a do Cairo (1960), eventos nos quais foram discutidos processos de solidariedade entre os países do hemisfério Sul, Ásia, África e América Latina.

É nesse momento, como vimos acima, na trajetória de Verger e os seus diálogos interculturais, que o Brasil estreitará relações diplomáticas com países como a Nigéria, o antigo Daomé (hoje Benin), Gana e o Senegal. Todavia, o recrudescimento interno da política brasileira, que resultou na instauração da ditadura militar, deu fim a essa agenda de diálogos diplomáticos com essa parcela da África, um desencontro que será notado por grupos da diáspora religiosa que aqui construíram as bases do candomblé no Brasil.

A segunda onda dessas relações diplomáticas entre Brasil e África foi direcionada aos países africanos lusófonos. Ao longo do governo militar, seguindo o jargão do pragmatismo ecumênico e responsável, a política externa brasileira se voltou para um multilateralismo despido de ideologias, pautado muito mais nos ditos interesses nacionais, segundo os quais o antigo império português, na África, representava a inserção internacional brasileira em regiões estratégicas. Não sem razão, entre 1972 e 1981, as transações comerciais de empresas brasileiras na África triplicaram (Milhorance, 2013), o que constitui muito mais um exercício de pragmatismo e de profunda racionalidade do que, necessariamente, a retomada de afinidades identitárias interrompidas.

As décadas de 1980 e 1990, por sua vez, 
representaram a descontinuidade dessa sanha eufórica rumo às oportunidades do continente africano. Nesse momento, a política externa brasileira não se lançou nem para a África lusófona, nem para a memória ancestral iorubana. A crise econômica, própria da década de 1980 e dos anos 1990, aliada à estratégia de uma política externa mais ligada ao Norte, fez desse período um momento de interrupção das relações Sul-Sul do Brasil em relação à África.

Foi justamente na era Lula que, institucionalmente, o país empreendeu esforços em prol do retorno estratégico do diálogo diplomático com a África e, nesse mesmo caminho, as ações de cooperação internacional. É nesse momento que os discursos da cooperação Sul-Sul ganham status de política de Estado, sendo essa modelagem de política externa uma verdadeira estratégia de captação de prestigio regional do Brasil no eixo Sul.

Não sem razão, o discurso do Estado brasileiro em torno da cooperação Sul-Sul bem como de outros Estados em desenvolvimento do Sul em condição de solidariedade, tais como, China, Índia e África do Sul - reside em reivindicar para si a complementariedade e a diferenciação em relação ao modelo de cooperação Norte-Sul (Milani e Carvalho, 2013). A horizontalidade nas relações, a ausência de condicionalidade das agendas e a menor assimetria entre doador e recebedor seriam elementos diferenciais dessas relações de solidariedade Sul-Sul, senão entre iguais, ao menos entre Estados com trajetórias e origens comuns.

Esse discurso não deixa de ser, em verdade, o uso (e abuso) de uma contrarretórica de poder por parte dos países em desenvolo i vimento, que estão hoje em condição de doar

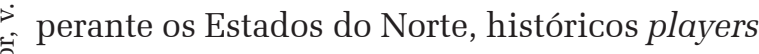
da cooperação internacional. Nesse sentido, o discurso da solidariedade, ao mesmo tempo em que incorpora sua legitimidade a partir do apelo das identidades regionais compartilhadas, das experiências históricas de matriz colonial e dos esforços comuns em prol do de- senvolvimento, trazem, de maneira explícita (e ao mesmo tempo sutil), um questionar do sistema de governança global, ao mesmo tempo em que reivindica a reforma desse sistema.

O Brasil, que agora, mais uma vez, dialoga com a África por meio da dita "diplomacia solidária”, o faz, também por interesses, como é comum em toda política externa. Todavia, as intermitências históricas do nosso tratar com a África dão conta do caráter ainda eventual e instável desses vínculos diplomáticos em construção. Esse é um aspecto que lança a incerteza quanto à continuidade dessa agenda, sobretudo diante das contenções financeiras que ora se anunciam com a crise econômica e das prováveis rupturas na condução da política externa quando da troca de governo.

\section{A VINDA DO REI DE OYO E A MOBI- LIZAÇÃO DO ESTADO POR PARTE DOS TERREIROS DE CANDOMBLÉ: um episódio de cooperação sul-sul à parte?}

Em meados de 2014, a Bahia foi palco de um encontro ancestral bastante significativo com a mítica África iorubana. A partir de uma ampla articulação política, as comunidades tradicionais de terreiro da Bahia foram capazes de mobilizar atores governamentais do Brasil e da Nigéria em prol da vinda da comitiva do Alaafin de Oyo, Obá Ladeyemi III para o Brasil. Esse rei tradicional, além de ser considerado o descendente direto de Odudua, o fundador e primeiro ancestral dos iorubás no mito da criação do mundo, tem, também, um papel cultural e espiritual, por ser considerado o herdeiro da coroa do rei Xangô.

Conta a historiografia iorubana que foi durante o reinado do rei Xangô, o terceiro Alaafin de Oyo, que essa cidade conseguiu garantir sua expansão e soberania sobre todos os territórios vizinhos. É justamente por esse motivo, que o Alaafin de Oyo, até os dias de hoje, é considerado o pai e guardião da cultura 
iorubana, sendo todas as outras coroas iorubanas hierarquicamente vinculadas à dele.

Se levarmos em conta que a maioria das comunidades tradicionais de matriz africana de tradição iorubana no Brasil costumeiramente guarda o culto a Xangô no rol de seus patrimônios imateriais, não é de se espantar a relevância desse encontro mítico para essa parcela da população brasileira. E, no caso do estado da Bahia, essa percepção é ampliada, já que, dos nove patrimônios negros salvaguardados pelo Instituto do Patrimônio Histórico e Artístico Nacional (IPHAN), oito deles se encontram nesse estado, e que, diretamente, cinco deles têm o culto a Xangô como ponto alto de seus patrimônios imateriais. Mais do que um encontro de natureza religiosa, como é o caso das visitas do papa, de bispos protestantes, de monges budistas ou qualquer outra liderança religiosa, esse foi um momento redentor para os processos de reconhecimento da narrativa negra no Brasil. Em um país que passou pela experiência da escravidão e cujas expressões religiosas de matriz africana tiveram papel definitivo nos processos de articulação e emancipação social do negro, esse momento significou o reencontro dos descendentes da diáspora de outrora causada pela indústria colonial escravagista.

As ações de salvaguarda do Instituto $\mathrm{Na}$ cional de Preservação do Patrimônio Histórico e Artístico Nacional (IPHAN) pela via do tombamento de terreiros matriciais de origem ioruba - Ilé Osúmaré Araká Asé Ogodo (Casa de Oxumarê), Ilé Asé Iyá Nasso Oká (Casa Branca), Ilé Asé Opo Afonjá (Terreiro do Afonjá), Ilé Iyá Omi Asé Iyamasé (Terreiro de Gantois) e Ilé Maroialaji (Terreiro Alaketu) - geram, para o Estado brasileiro, o dever de responsabilidade e o constrangimento de guarda por esse legado nacional, no qual a Bahia figura como a unidade da federação em que mais se manifestam essas tradições originarias da cidade nigeriana de Oyo.

Não sem razão, ao tomar conhecimento das casas de candomblé no Brasil e de suas vinculações com a tradição iorubana, o próprio Alaafin, por meio do antropólogo Fabio Lima $^{5}$ e do Baba Sivanilton Encarnação da Mata, ${ }^{6}$ pediu apoio para que as cinco casas tombadas ajudassem a compor uma mobilização transnacional capaz de sensibilizar o governo nigeriano em prol da preservação da cidade de Oyo e da consequente indicação dela como Patrimônio Universal da Humanidade pela UNESCO. Com o avanço do islamismo entre os agentes de Estado que compõem a própria burocracia oficial nigeriana, a tradição iorubana e, consequentemente, a cidade de Oyo, por remeter o país às tradições de uma Nigéria de outrora, não goza da boa vontade política para o exercício dessa salvaguarda.

Respondendo ao apelo, as cinco comunidades tradicionais tombadas envidaram esforços no sentido de mobilizar o Estado brasileiro em prol desse objetivo, num verdadeiro exercício de paradiplomacia desses atores com o fito de mobilizar a diplomacia oficial brasileira para uma causa que também diz respeito ao país, qual seja, seu dever de também salvaguardar esse patrimônio compartilhado entre o Brasil e a Nigéria. Nesse sentido, a agenda da cooperação Sul-Sul, utilizada politicamente de modo reverso, serviu de constrangimento discursivo dessas comunidades para a mobilização de órgãos do executivo nacional, a exemplo do Ministério das Relações Exteriores, do Ministério da Cultura e da Secretaria da Promoção da Igualdade Racial, bem como de órgãos do executivo do governo do estado da Bahia e da própria prefeitura de Salvador.

${ }^{5}$ Vale notar que o antropólogo baiano Fabio Batista Lima publicou, recentemente, a obra intitulada Africa e Ancestralidade, na qual relata sua viagem a Oyo, tendo como ponto de partida suas impressões etnográficas desse encontro, uma diáspora que culmina com a visita do Alaafin de Oyo à Bahia, em meados de 2014.

${ }^{6}$ Momento importante nesse processo de articulação política é justamente a visita do sacerdote de matriz africana Sivanilton da Encarnação da Mata a Oyo, na qual esse ator firma o compromisso, junto ao Alafin, cumprir o papel de adido cultural de Oyo no Brasil, uma aliança que termina por gerar toda essa agenda de mobilizacão política por parte das casas tradicionais de matriz iorubana tombadas pelo IPHAN. 


\section{CONSIDERAÇÕES FINAIS}

O quadro desenhado neste artigo, ao tentar ilustrar essa construção identitária dos patrimônios negros de matriz iorubana no Brasil e os seus respectivos desdobramentos na agenda de formulação de políticas de cooperação Sul-Sul, lançou luzes sobre os processos descontínuos e intermitentes dos impulsos do Brasil rumo à África desde os navios negreiros até os dias atuais. Mais do que dar conta dessas relações aqui apresentadas (que certamente são muito mais complexas do que relata esta versão), pretendemos apresentar outra perspectiva da cooperação Sul-Sul, a partir de uma qualidade de atores historicamente negligenciados nas narrativas oficiais: os descendentes da diáspora negra.

Em que pese a beleza do encontro da diáspora iorubana, na figura do Alaafin de Oyo, os seus desdobramentos são bastante questionáveis do ponto de vista de uma agenda com frutos mais efetivos. A agenda, que tinha promessas de uma política de cooperação e integração cultural compartilhada, sequer saiu do papel. Até o presente momento, o IPHAN, órgão técnico nacional, expert em políticas de salvaguarda, não chegou a ser contatado pelo governo nigeriano para se iniciar um processo de cooperação técnica no campo da salvaguarda de patrimônio cultural material e imaterial. Embora seja lamentável, na condição de Estado soberano, a Nigéria goza dessa prerrogativa westfaliana, não restando alternativa ao Brasil, senão a de respeitar. Por outro lado, no rol das emergências institucionais, as burocracias do IPHAN e do próprio Ministério das Relações É Exteriores não parecem muito motivadas para \& a consecução dessa agenda Sul-Sul que, em iิ certa medida, extrapola suas limitações de quadros funcionais e de competência.

Já no plano nacional, as relações entre as comunidades tradicionais de terreiros e esse órgão de salvaguarda ainda é pautado por ambivalências, contradições e paradoxos. Essas são as marcas do processo brasileiro de institucionalização da ideia de patrimônio cultural, um cami- nhar que, desde sua origem, ao não reconhecer de modo equânime todas as contribuições étnicas formadoras da memória coletiva, criou para si um débito histórico que carece de correção para o bem da narrativa nacional. Reivindicase, desse modo, a necessidade de se construir uma narrativa histórica capaz de contemplar as pluralidades nacionais, algo que estaria atrelado ao reconhecimento das diversas contribuições prestadas pelas distintas matrizes étnicas que forjaram o país, a exemplo dos índios, dos negros (bantos e sudaneses), dos nipônicos, dos itálicos, dentre tantos outros negligenciados em favor da memória heroica e católica. Essa seria uma das condições fundamentais para a construção de um Estado multiétnico, centrado na ideia de democracia e respeito aos direitos humanos, sobretudo, no que concerne ao direito à memória.

No caso dos patrimônios negros, por exemplo, temos ainda um profundo déficit étnico em relação aos objetos de salvaguarda nacional, uma tensão que dá conta de uma negligência histórica ainda a avançar. Os refluxos rumo às expressões de Mama África mítica não devem ser apenas um esforço de indivíduos forjados pela diáspora, mas uma política de Estado para a salvaguarda de sentido de Brasil. Nesse âmbito, a cooperação Sul-Sul deveria, sim, nos ajudar a cumprir esse papel.

Entretanto, o jogo de interesses diplomáticos não nos deve enganar. Em que pese a relevância dessa agenda, inclusive para a conformação da memória nacional, essa não é uma prioridade assumida politicamente pelo Estado brasileiro. Abraçar uma política de ganhos solidários de efeito meramente simbólico, como é o caso da salvaguarda compartilhada do patrimônio cultural de Oyo, sobretudo quando essa solidariedade vai de encontro às estruturas soberanas da Nigeria, por certo passa a não coadunar com a prudência neutral dessa tecnologia cooperante do Sul, que se vangloria por não aplicar condicionalidades, ainda que elas sejam meritórias.

Recebido para publicação em 03 de setembro de 2015 Aceito em 20 de dezembro de 2015 


\section{REFERÊNCIAS}

ALBERTO, Paulina L. Para africano ver: intercâmbios africano-baianos na reinvenção da democracia racial, 1961-1963. Afro Ásia, Salvador, n. 44, p. 57-149, 2011.

ANTONIL, A. J. Cultura e opulência do Brasil por suas drogas e minas. São Paulo: Itatiaia, 1982.

BRANDÃO, Maria do Carmo; MOTTA, Roberto. Adão e Badia: carisma e tradição no xangô de Pernambuco. In: SILVA, Vagner Gonçalves da. (Org.). Caminhos da Alma: Memória Afro-Brasileira. São Paulo: Summus (Selo Negro), 2002.

BRAGA, Júlio. Na gamela do feitiço: repressão e resistência nos candomblés da Bahia. Salvador: CEAO/Edufba, 1995.

CASTRO, Yeda Pessoa de. Falares Africanos na Bahia: um vocabulário Afro-Brasileiro. Rio de Janeiro: Topbooks, 2001

Costa, Valéria G. Trajetórias negras: os libertos da Costa d'Africa no Recife, 1846- 1890. (Tese) UFBA, Salvador, 2013.

FREYRE, Gilberto. Casa-grande \& senzala: formação da família brasileira sob o regime da economia patriarcal. São Paulo: Global, 2006.

HIRST, Monica. As relações Brasil-África em ritmo de cooperação Sul-Sul. Cebri, julho, 2010.

LIMA, Fabio Batista. Diáspora e Ancestralidade. Salvador: KAWO-KABIYESILE, 2015.

MILANE, Carlos Roberto Sanchez; CARVALHO. Tassia C O. Cooperação Sul Sul e política externa: Brasil e China no continente africano. Estudo Internacionais, v. 1, n. 1 , jan- jun, 2013, p 11-35.

MILHORANCE, Carolina. A política de cooperação do Brasil com a África Subsaariana no setor rural: transferência e inovacão na difusão de políticas pública. Revista Brasileira de Relações Internacionais, v. 56, n. 2 p 5-22, 2013
MOURA, Clovis. Dicionário da escravidão negra no Brasil. São Paulo: EDUSP, 2004.

MUNANGA, Kabengele. Origens africanas do Brasil Contemporâneo. Histórias, Línguas, Culturas e Civilizações. São Paulo: Global, 2009.

PRANDI, Reginaldo. De africano a afro-brasileiro: etnia, identidade, religião. Revista USP, São Paulo, n. 46, p. 52-65, jun./ago. 2000. Disponível em: http://www.usp.br/ revistausp/46/04-reginaldo.pdf

QUADROS, Jânio. Brazil's new foreign polyce. Foreign Affairs, out. 1961

RODRIGUES, Raimundo Nina. Os africanos no Brasil. Brasília: Editora UNB, 2004.

SANTOS, Deoscóredes M. dos. História de um terreiro nagô. São Paulo: Max Limonad Editora, 1988.

SARAIVA, José Flávio S. África parceira do Brasil Atlântico: relacões internacionais do Brasil e da Africa no início do século XXI. Belo Horizonte: Fino Traço, 2012.

SILVA, Angela F. Que eu vou na terra dos negros: circularidades atlânticas e a comunidade brasileira na África. (dissertação) USP, 2010.

TELES DOS SANTOS, Jocélio. O poder da cultura e a cultura no poder: a disputa simbólica da herança cultural negra no Brasil. Salvador: EDUFBA, 2005.

UNESCO. História Geral da África. V: África do século XVI ao XVIII. Brasília: UNESCO, 2010.

VERGER, Pierre. Fluxo e refluxo do tráfico de escravos entre o Golfo do Benin e a Bahia de Todos os Santos: dos séculos XVII a XIX. Salvador: Corrupio, 1987. 


\section{BAHIA AND ITS FLUXES AND REFLUXES TOWARDS MYTHICAL MAMA AFRICA: a possible field for the exercise of the South-South cooperation?}

\author{
Andre Luis Nascimento dos Santos \\ Marcos Fábio Rezende Correia \\ Paulo Victor de Oliveira
}

This article reflects upon the fluxes and refluxes between Brazil and the mythical Africa of Yoruban matrix. Methodology will include sociology of actors and post-colonial readings - interpretations of social relations that helped establish the dialectic links between the actors, structures and institutions at play. Throughout the text we will use academic and literary reports by intellectuals of human sciences who, over the last century, established these transits between Brazil and Yoruban Africa, with special attention for the participation of Martiniano Eliseu do Bonfim, Pierre Verger and Agostinho da Silva. In place of drawing conclusions, we analyze the contemporary conjecture of the South-South cooperation in light of an event in which Brazil was invited to support Yoruban cultural preservation in Africa with the safeguard of Oyo historical site, that is, the mythical kingdom of King Shango.

KeYwords: Africa, Yoruban people, candomble, external politics, South-South cooperation.

\author{
Andre Luis Nascimento dos Santos \\ Marcos Fábio Rezende Correia \\ Paulo Victor de Oliveira
}

Cet article réfléchit sur les flux et reflux entre le Brésil et l'Afrique mythique yoruba. Comme méthodologie, nous allons utiliser la sociologie des acteurs et lectures postcoloniales, comme des interprétations des relations internationales qui nous permettent d'établir les liens dialectiques entre les acteurs, les structures et les institutions en jeu. Nous allons utiliser des récits académiques et littéraires apportés par les intellectuels des sciences humaines qui, dans le cours du siècle dernier, ont établi ces transits Brésil-Afrique yoruba, avec un accent particulier sur le rôle de Martiniano Eliseu do Bonfim, Pierre Verger et Agostinho da Silva. Pour finir, nous analysons la situation actuelle de la coopération Sud-Sud à la lumière de l'invitation à l'Etat brésilien de soutenir la préservation de la culture yoruba en Afrique, par la protection du site historique d'Oyo, qui est le royaume mythique du roi Xangô.

Mots-CLÉ: Afrique, peuple yoruba, candomblé, politique extérieure, Coopération Sud-Sud

Andre Luis Nascimento dos Santos - Ogã de Xangô (Casa de Oxumarê), Doutor em Administração pela UFBA (estágio doutoral na Science Po Toulouse - França), professor adjunto I da Universidade Federal de Alagoas (UFAL) e atualmente coordenador do curso de Administração, Campus de Arapiraca.

Doutor em Administração. Professor da Universidade Federal de Alagoas no curso de Administração e Administração Pública do Campus de Arapiraca. No que concerne à pesquisa, se dedica a análise do mundo contemporâneo e das interações entre o Internacional e o Local, a influência das Organizações Internacionais tais como o Banco Mundial, a União Europeia e a UNESCO no desenvolvimento de políticas públicas na América Latina (Argentina, Brasil e México). Atualmente, tem se dedicado ao campo da cultura brasileira e a salvaguarda da memória afro brasileira. Publicações recentes: Brasil. Novas agendas sócio-políticas por novos pactos sociais ainda instáveis. Estabilidades futuras serão possíveis?. Cadernos Gestão Social, v. II, p. 175/-183, 2010; Administração Política: entre o passado e o futuro, a escolha de uma tradição a ser seguida. REBAP. Revista Brasileira de Administração Política, v. 4, p. 30, 2010; Banco Mundial e a agenda de Reforma do Judiciário: Uma breve análise do binômio retórica ação. Relações Internacionais no Mundo Atual, v. 09, p. 1/147-197, 2009.

Marcos Fábio Rezende Correia - Ogã de Ewá (Casa de Oxumarê). Mestrando em Desenvolvimento e Gestão Social na Faculdade de Administração da Universidade Federal da Bahia (UFBA).

Paulo Victor de Oliveira - Adosu Iemanjá. Mestrando em Sociologia pela Universidade Federal de Alagoas. 